\title{
Innovative Research on the Basic Theory of Specialty Construction and Discipline Construction
}

\author{
Qian Xiang ${ }^{1, *}$ \\ ${ }^{1}$ Sichuan Minzu College, Kangding, Sichuan, China \\ *Corresponding author. Email:343722259@qq.com
}

\begin{abstract}
The purpose of specialty construction lies in the cultivation of specialized talents. What needs to be solved is the problem of what knowledge to impart, how to impart knowledge, and how to impart knowledge with high efficiency; the purpose of discipline construction is to build, innovate and improve the knowledge system. The problem to be solved is how to ensure that the professional knowledge system keeps pace with the times, and is cutting-edge and innovative. Knowledge is the bridge between discipline construction and specialty construction. Discipline construction provides knowledge system support for specialty construction, specialty construction provides high-quality human resources support for the development and improvement of discipline construction, and specialty construction indicates the direction of development for discipline construction.
\end{abstract}

Keywords: Specialty construction, Discipline construction, Knowledge system.

\section{INTRODUCTION}

Specialty construction and discipline construction are the unavoidable themes of the connotative development of colleges and universities. However, in the actual construction process, due to the vague understanding of the connotation and interrelationship of specialty construction and discipline construction, colleges and universities often fall into chaos and disorder in the content and thinking of discipline and specialty construction. In response to this situation, the author will focus on the connotation of the two concepts of specialty and specialty construction, discipline and discipline construction, in order to construct a systematic basic theoretical study on the relationship between specialty construction and discipline construction.
*Project: Educational Reform Project: This article is the 2019 National Ethnic Affairs Commission Higher Education Teaching Reform Research Project of Sichuan Minzu College, a school-level project "Research on the Construction Path of Applied Demonstration Course 'Golden Course' in Colleges and Universities in Ethnic Areas"

\section{SPECIALTY AND SPECIALTY CONSTRUCTION}

\subsection{Connotation of Specialty}

What is a "specialty"? The interpretation in "Ci Hai" is "academic categories established by higher education institutions or secondary professional schools according to the needs of the division of social specialties". Chinese institutions of higher learning and secondary professional schools set up various specialties in accordance with the needs of the country's construction and the nature of the schools. Each specialty has its own teaching plan to achieve the professional training goals and requirements. From the perspective of conceptual analysis, the concept of "specialty" has four connotations:

- The main body of specialty establishment is the higher education or technical secondary schools.

- The establishment of specialties is based on the needs of social professional division of labor, national construction needs and the nature of the schools. 
- The elements of specialty composition include teaching plan, specialty training objectives and specialty training requirements.

- The essence of the specialty is the academic category.

Since the primary function of colleges and universities is to cultivate talents, at the same time, combined with the connotation of the concept of "specialty", the purpose of specialty establishment is to cultivate various specialized talents in a planned way according to the country and society's talent needs. From this perspective, specialty is the bridge between social needs and the cultivation of talents in colleges and universities. For what kind of talents the society needs, colleges and universities set up relevant specialties according to their actual conditions to achieve the cultivation of specific talents.

\subsection{The Essence of Specialty Construction}

Since the purpose of specialty establishment is to cultivate specialized talents, and specialty construction is a description of the professional development process. From this perspective, specialty construction is the process of cultivating professional talents in colleges and universities, and the professional talents cultivated are the core results of specialty construction. So how does specialty construction achieve the goal of training specialized talents?

In this regard, judging from the comparative status of the educated before and after training, the most significant difference lies in the difference in the educatees' learning and mastery of specialized knowledge. It can be seen that the process of cultivating talents in specialty construction is the process of systematically imparting professional knowledge to the educated by colleges and universities through planned teaching activities. From this perspective, the essence of specialty construction lies in the teaching of professional or specialized knowledge in order to cultivate specialized talents.

\subsection{Content of Specialty Construction}

In order to ensure the effect of specialty construction, it is a necessity to promote the efficient transfer of specialized or professional knowledge, and achieve high-quality training of specialized talents. It is necessary to strengthen specialty construction from the following aspects:
First of all, the question of what kind of specialized talents should be cultivated need to be clarified, that is, the goals and standards of talent cultivation. Different types of specialized talents have different talent training standards, and the knowledge, skills, and ability requirements that they should master are vastly different, thus forming specialized and targeted specialized talent training programs with their own characteristics.

Secondly, it is the issue of clarifying what knowledge can be imparted to achieve the goal of specialized talent training, that is, the formulation of a talent training plan, which mainly includes the construction of curriculum content, the content and proportion of practical teaching and theoretical teaching, the time of curriculum, and the hours and requirements of curriculum. The implementation of different talent training programs will inevitably bring about different talent training effects.

Thirdly, it is to clarify the question of how to impart knowledge more efficiently, that is, the reform of teaching methods, including theoretical teaching reform, practical teaching mode reform, experimental training form, second classroom teaching, bisection classroom, rain classroom, and innovations in new teaching methods such as a shared teaching platform built by the Internet.

Fourthly, the quality requirements of teachers who impart knowledge and how to train and improve teachers' professional knowledge and teaching level, namely, the construction of the teaching staff, including the standards, methods and types of teacher introduction, teacher training and further education system, methods and requirements, teacher maintenance, and teacher teaching quality evaluation.

Finally, how to ensure that the knowledge imparted is frontier and forward-looking, that is, the construction of teaching materials. Its significance is to ensure that the knowledge imparted can keep up with the development of the times and that the people trained can meet the needs of society.

\section{DISCIPLINE AND DISCIPLINE CONSTRUCTION}

\subsection{The Connotation of Discipline}

There are two interpretations of "discipline" in "Ci Hai":

- Academic classification, referring to a certain scientific field or a branch of science. Such as 
chemistry and physics in natural sciences; law and sociology in social sciences.

- The abbreviation of "educational subject", also called "subject", it is a unit with a certain range of knowledge and skills organized according to logical procedures in teaching. Such as General Psychology, Child Psychology, Educational Psychology in the Department of Psychology of Higher Schools.

Whether it is "academic classification" or "educational subject", the discipline concept contains a strong "knowledge system".

In this regard, China's academic circles also believe that the so-called discipline is an organizational system composed of a group of scholars and scholars who rely on a certain material basis to create, transmit, integrate and apply knowledge. It is a real academic organization system with organizational form. [1] ${ }^{1}$ Compared with the interpretation of "Ci Hai", the academic circles' understanding of the discipline is more systematic, with at least four levels of connotations:

- Knowledge is the core element of the discipline;

- Scholars are the intellectual support for the development of the discipline;

- The purpose of discipline development is the creation, transmission, integration and application of knowledge.

- The construction of disciplines is limited by the objective material world and serves the objective material world.

It can be seen from the above that knowledge is the core element of the concept of "discipline". From the perspective of knowledge form, a discipline is a knowledge system built around the inheritance, creation, fusion and application of knowledge, which is composed of specific logical procedures.

\subsection{The Essence of Discipline Construction}

Discipline construction is the description of the discipline development process. The process of discipline construction is the process of inheriting knowledge, discovering knowledge, innovating knowledge and producing results, and its core is the construction, innovation and improvement of the knowledge system. Discipline construction in the sense of a modern university presents three forms,

1 Lu Jun, Song Xiaoping, Lu Shuyun, Discussion of Relevant Concepts on Disciplines and Disciplines Building [J]. Research on Education Tsinghua University, 2004, 12. namely, the form of discipline organization, the form of discipline knowledge, and the form of discipline activity. [2] $]^{2}$ The problems to be solved respectively are:

First of all, the problem to be solved by the discipline organization form is how to ensure the orderly and sustainable development of discipline construction through organizational structure construction. The focus is on the establishment and functions of related discipline construction organizations.

Secondly, the problem to be solved by the form of discipline knowledge is how to determine discipline development direction and discipline development goals according to the current situation of school specialty construction. The focus is on coordinating the integrated relationship between discipline construction and specialty construction, that is, how to ensure that the transfer of knowledge and the innovation of knowledge can promote each other.

Finally, the problem solved by the discipline activity form is what measures should be taken to ensure that the discipline construction is promoted in accordance with the determined discipline development direction and goals. The focus is on the formulation of discipline construction plans, implementation methods and evaluation systems that are compatible with the development direction and goals of the discipline.

\subsection{The Content of Discipline Construction}

Analyzing the above three forms of discipline construction, it can be seen that the main contents of discipline construction include:

\subsubsection{Construction of Disciplinary Echelon}

The discipline echelon is the organizational guarantee for discipline construction, the key to the sustainable development of disciplines, and the core of discipline construction. The key to the construction of the discipline echelon is to form an appropriate teacher echelon with a reasonable structure of professional titles, a sufficient number of teachers, and good scientific research capabilities, which can make the teaching and scientific research of various disciplines and specialties be in a dynamic balance of continuous renewal, alternation and development. The difficulties of discipline echelon construction are

2 Kang Cuiping, The Three Patterns and the Policy Construction of Discipline Development in Universities [J]. Journal of Higher Education, 2015, 11. 
how to strengthen discipline team building, to properly handle the interest relationships between team members, and to actively cultivate team spirit, as well as to form a research group with the same academic philosophy, clear academic pursuit, and strong cohesion under the influence of the academic leader's organization. [3] ${ }^{3}$

\subsubsection{Direction of Disciplinary Development}

The choice of discipline direction is the most important issue in discipline construction. When choosing a subject, the main factors that need to be considered are:

- It requires comprehensive consideration of the original research foundation and advantages of the school, discipline or specialty.

- The selection of subject direction must have high academic value or greater practical significance, with overall and leading nature.

- The subject direction should be relatively stable, forward-looking and expansive. $[4]^{4}$

- The selection of subject direction should be consistent with the direction of specialty construction to realize the integration of subject andspecialty construction.

\subsubsection{Goals of Disciplinary Development}

Disciplinary development goals are the expected positioning of the strategic development of the discipline construction. It is not only the inner development spiritual power of the discipline construction, but also the specific requirements of the current "double first-class" construction in China's colleges and universities.

\subsubsection{Plan of Disciplinary Development}

The discipline development plan is the core part and essence of the discipline construction plan. The formulation of the discipline development plan focuses on answering the following four questions:

- "Where it should be", that is, it is necessary to accurately grasp the discipline echelon, discipline construction status and local characteristics, such as the structure of teachers, discipline advantages, local talent

3 Lei Zhaohai, On the Disciplinary Construction at the Higher Institutions of China [J]. Journal of Yunnan Nationalities University:Social Sciences, 2008, 11

4 Zheng Xiangjin, Reflections on Selection \& Conformity of Key-Subject Direction in University [J]. Theory and Practice of Education, 2005, 25. demand characteristics, etc., and have a comprehensive and in-depth understanding.

- "Where to go", this requires to rationally determine the phased construction goals of discipline construction, that is, to put forward specific development goals for future construction in phases according to the difficulties faced by the current discipline construction

- "How to go", this means to plan the action path of the discipline team in detail, and propose specific methods to achieve the goal according to the established phase goals of discipline construction.

- "What is needed", it is to scientific analyze the guarantee system for the development of disciplines, that is, to pay attention to the external requirements of discipline construction, and carry out a specific analysis of the material guarantee and support system required to achieve the goal.

All in all, the plan of disciplinary development is based on the current status of discipline construction, in view of the current difficulties faced by discipline construction and development, and at the same time, combining discipline development direction and goals, establishing phased and specific construction requirements, and using the external environment of discipline construction to propose practical and feasible solutions and action paths.

\subsubsection{Construction of Curriculum System}

Construction of curriculum system is the main carrier of the knowledge system in discipline construction, and it is also the main basis for specialty construction. Curriculum is an important indicator reflecting the subject system and level. The curriculum absorbs nutrients from the achievements of discipline construction, reflects the latest relationship between the subject and the development of social economy, science and technology, and culture in a timely manner, so that students are exposed to disciplinary knowledge that reflects the frontier of the discipline. For this reason, the main problem to be solved in the construction of the curriculum system in the discipline construction is how to transfer the results of the discipline construction to the students in the form of courses in time.

\subsubsection{Construction of Discipline Platforms}

The development and growth of the discipline cannot be separated from the discipline platforms that 
serve as the soil and support. The so-called discipline platforms refer to the external physical conditions such as places, equipment, facilities, and means that must be relied on to carry out the disciplinary activities $[5]^{5}$, and they also include the construction of virtual network discipline platforms based on network information technology. For example, from the perspective of the "Internet + " platform, the construction of a discipline platform characterized by resource sharing formed by universities and governments, universities and colleges, universities and enterprises, and within the universities.

\subsubsection{Disciplinary Achievements}

Disciplinary achievements are the crystallization of knowledge of discipline construction and innovation, and their main manifestations are: quality curriculum construction, textbook construction, academic papers, monographs, teaching and research papers, application transformation of results, patents, inventions, and other innovative research results.

\subsubsection{Discipline Environment}

The so-called discipline environment refers to the integration of various policies, concepts and other related factors within colleges and universities that can affect teachers' motivation and enthusiasm for participating in knowledge innovation, achievement application and achievement transformation. For example, the relevant scientific research award policies formulated within colleges and universities and the academic achievement evaluation system linked to the evaluation of professional titles are all within the category of the discipline environment.

\section{THE RELATIONSHIP BETWEEN SPECIALTY CONSTRUCTION AND DISCIPLINE CONSTRUCTION}

To sum up, the purpose of specialty construction is to cultivate specialized talents, and what to be solved is the question of what knowledge to impart, how to impart knowledge, and how to impart knowledge efficiently. The purpose of discipline construction is the construction, innovation and improvement of the knowledge system. The problem to be solved is how to ensure that the specialty knowledge system advances with the times and is cutting-edge and innovative. It can be seen that

\footnotetext{
$5 \quad$ Zhang Shulin, Pei Xu, Exploration and Thinking on the Construction of Intensive Subject Platforms in Universities [J]. Academic Degrees \& Graduate Education, 2004, 06.
}

knowledge is the bridge between discipline construction and specialty construction. The specific relationship between the two is:

\subsection{Disciplinary Construction Provides Knowledge System Support for Specialty Construction}

First of all, professional knowledge can be updated in a timely manner through discipline construction, ensuring that the specialty knowledge imparted through specialty construction is highly synchronized with social development, is forwardlooking and cutting-edge, can greatly improve the quality of professional talent training, and achieve a high degree of integration between the quality of talent training and the demand for social talents.

Secondly, through discipline construction and scientific research, it can effectively improve the overall quality of the faculty and teachers' teaching and scientific research capabilities, which is conducive to effectively transforming subject resources into professional teaching resources, promoting teaching through research, and realizing the integration of discipline construction and specialty construction. [6] ${ }^{6}$ At the same time, transforming high-level discipline construction results into curriculum professional knowledge can also greatly stimulate students' interest in specialty learning, thereby improving the quality of talent training.

Finally, through the continuous accumulation of discipline advantages in discipline construction, it can realize the individualized and characteristic development of specialty construction. Because of subject advantages, strong subject direction, firstclass scientific research team, high-quality scientific research projects and good scientific research environment, etc., they will all have a positive impact on the curriculum system construction and teaching content reform of related majors, which will help promote the formation of specialties with special advantages.

6 Yuan Guanglin, To Integrate Discipline with Specialty: A Strategy for Developing New Colleges of Undergraduate Education [J]. Journal of Higher Education Management, 2016, 03. 


\subsection{Specialty Construction Provides High- quality Human Resources Support for the Development and Improvement of Discipline Construction}

Specialty construction is the process of talent training, especially high-level specialty construction is an important channel for cultivating a large number of innovative talents with scientific research spirit, scientific research ability and innovative spirit. In particular, the early exposure of undergraduates to a large number of latest research results can greatly stimulate students' interest in professional research, thereby providing a fresh force for promoting the development of disciplines and improving the level of scientific research.

\subsection{Specialty Construction Indicates the Direction of Development for Discipline Construction}

Specialty construction with talent training as the core, and the talents trained to adapt to local economic and social development services, is a key indicator of the social value of specialty construction. The talents who need to master what knowledge and skills the society needs will become the guide for knowledge transfer in specialty construction. Therefore, the overall planning of discipline construction oriented to the needs of specialty construction is not only an inevitable way to ensure that discipline construction is linked to social needs, but also an effective means to ensure that discipline construction has social value.

\section{CONCLUSION}

All in all, the discipline construction and specialty development of colleges and universities complement each other, promote each other, and coexist. The core of discipline construction is the construction, innovation and improvement of knowledge systems; the core of specialty construction is the training of specialized talents. The former focuses on the innovation of professional knowledge, and the latter focuses on the transmission of professional knowledge; knowledge is the bridge between discipline construction and specialty construction. Disciplinary construction is an important foundation for specialty construction, and specialty construction indicates the direction of discipline construction.

\section{AUTHORS' CONTRIBUTIONS}

This paper is independently completed by Qian Xiang.

\section{REFERENCES}

[1] Lu Jun, Song Xiaoping, Lu Shuyun, Discussion of Relevant Concepts on Disciplines and Disciplines Building [J]. Research on Education Tsinghua University, 2004, 12. (in Chinese)

[2] Kang Cuiping, The Three Patterns and the Policy Construction of Discipline Development in Universities [J]. Journal of Higher Education, 2015, 11. (in Chinese)

[3] Lei Zhaohai, On the Disciplinary Construction at the Higher Institutions of China [J]. Journal of Yunnan Nationalities University:Social Sciences, 2008, 11. (in Chinese)

[4] Zheng Xiangjin, Reflections on Selection \& Conformity of Key-Subject Direction in University $[\mathrm{J}]$. Theory and Practice of Education, 2005, 25. (in Chinese)

[5] Zhang Shulin, Pei Xu, Exploration and Thinking on the Construction of Intensive Subject Platforms in Universities [J]. Academic Degrees \& Graduate Education, 2004, 06. (in Chinese)

[6] Yuan Guanglin, To Integrate Discipline with Specialty: A Strategy for Developing New Colleges of Undergraduate Education [J]. Journal of Higher Education Management, 2016, 03. (in Chinese) 